\title{
Altered expression and modification of proteases from an avirulent mutant of Porphyromonas gingivalis W50 (W50/BE1)
}

\author{
Lucy M. Collinson, Minnie Rangarajan and Michael A. Curtis \\ Author for correspondence: Michael A. Curtis. Tel: +44 171 3770444. Fax: +44 1712473428. \\ e-mail: m.a.curtis@mds.qmw.ac.uk
}

MRC Molecular

Pathogenesis Group, Department of Oral

Microbiology, St

Bartholomew's and the

Royal London School of

Medicine and Dentistry,

Queen Mary and Westfield

College, University of

London, 32 Newark Street,

London E1 2AA, UK

\begin{abstract}
Proteases of Porphyromonas gingivalis are considered to be important factors in the virulence of this organism. A non-pigmenting mutant of $P$. gingivalis W50 (W50/BE1) has been shown to be less virulent in animal models and to produce significantly less Arg-specific protease activity than the parent strain. Three proteases are present in the culture supernatant of $P$. gingivalis W50: RI, RIA and RIB. All three proteases are derived from prpR1, which encodes a polypeptide of 1706 amino acids that is organized into distinct domains (pro, $\alpha_{1}$ $\beta$ and $\gamma$ ). The aim of the present investigation was to purify and characterize the Arg-specific proteases produced by the avirulent W50/BE1 strain. Significant differences were observed between the proteases of $P$. gingivalis W50 and W50/BE1. The levels of RI present in the culture supernatant of W50/BE1 were lower than those present in W50, and RIA and RIB were absent. RI from W50/BE1 was composed of three polypeptide chains, unlike the enzyme from W50, which is a heterodimer. The remainder of the Arg-specific protease activity in W50/BE1 was derived from a second gene, prR2, and was present in two fractions, RIIAs/BE (soluble) and RIIAV/BE (vesicle-bound). This activity contained two peptide chains: a $\sim 54 \mathrm{kDa}$ chain corresponding to the protease domain and $\mathrm{a} \sim 26 \mathrm{kDa}$ chain, derived from the propeptide domain of the PrRII precursor. No enzyme with large glycan additions, equivalent to RIB in the vesicle fraction of the wild-type W50, was present. These data indicate that the reduced level of extracellular protease activity in W50/BE1 reflects reduced synthesis and/or export of prpR1 enzymes, which is only partially compensated by synthesis of prR2-derived enzymes, and that all of these proteases undergo altered post-translational modification compared to the parent strain.
\end{abstract}

Keywords: Porphyromonas gingivalis, avirulent, extracellular arginine-specific proteases, altered modification

\section{INTRODUCTION}

Porphyromonas gingivalis has been implicated as one of the causal organisms in chronic adult periodontal disease. Virulence factors of this organism include haemagglutinins (Han et al., 1996; Hinode et al., 1995), fimbriae (Chandad \& Mouton, 1995) and extracellular proteases, of which those specific for Arg-x and Lys- $\mathrm{x}$ peptide bonds (Okamoto et al., 1996; Aduse-Opoku et al., 1995; Pike et al., 1994) have received the greatest

Abbreviations: DL-BRpNA, N $\alpha$-benzoyl-DL-arginine $p$-nitroanilide; L-BRpNA, N $\alpha$-benzoyl-L-arginine $p$-nitroanilide; DNS-EGRCK, 1,5-dansylGlu-Gly-Arg chloromethyl ketone, dihydrochloride; HMG, high-molecularmass gingipain. attention. Three forms of Arg-x proteases have been isolated, purified and characterized from $P$. gingivalis W50 culture supernatant in our laboratory (Rangarajan et al., 1997a). These are referred to as RI, RIA and RIB. $\mathrm{RI}$ is a heterodimer composed of a catalytic $\sim 54 \mathrm{kDa} \alpha-$ chain and an $\sim 58 \mathrm{kDa}$ adhesin $\beta$-chain, whereas RIA consists of the $\sim 54 \mathrm{kDa}$ catalytic $\alpha$-chain, and RIB consists of the $\alpha$-chain covalently modified with carbohydrate $(70-80 \mathrm{kDa})$. All three enzymes are derived from prpR1 (Aduse-Opoku et al., 1995). More recently, a second gene $(r g p b / p r R 2)$ has been identified which also encodes Arg-specific protease activity (Nakayama et al., 1995; Rangarajan et al., 1997b). Construction of a prpR1 isc genic mutant allowed analysis of the proteases from this second gene. Two enzymes, RIIA and RIIB, 

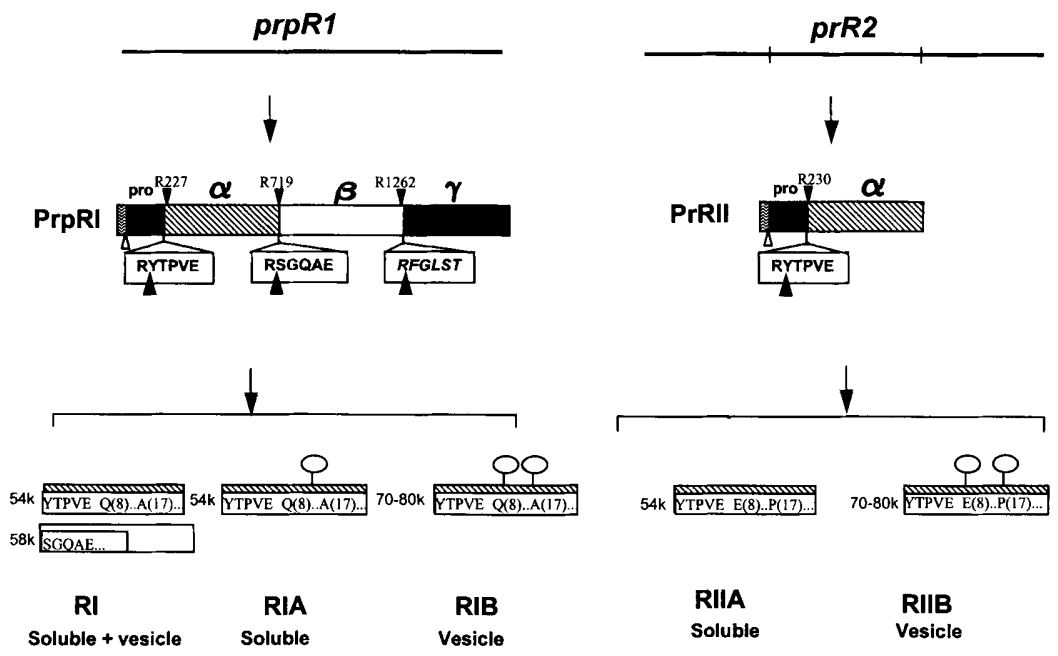

RIB
Vesicle

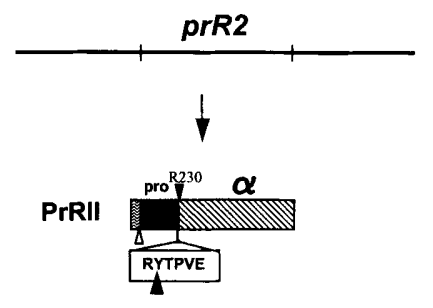

54k एTPVE E(8).P(17)

$70.80 \times$

RIIA

Soluble

RIIB

Vesicle

(Only seen in prpR1 mutants)

Fig. 1. Generation of Arg-specific proteases from PrpRI and PrRII in P. gingivalis. PrpRI (1706 amino acids) is organized into four domains: pro, $\alpha, \beta$ and $\gamma$. PrRll is organized into two domains: pro and $\alpha$. Vertical arrowheads above PrpRI indicate the positions of the proteolytic processing sites which generate the heterodimer RI. Arrows above PrRIl indicate the position of the processing site which generates RIIA and RIIB. The resulting $\mathrm{N}$-termini are shown below PrpRI and PrRII. (Note that the sequence at the junction of the $\beta$ - and $\gamma$ regions is in italics to indicate that this processing site is an assumption based on the molecular size of the $\beta$-component.) The open arrowhead marks the putative signal peptidase cleavage site. The monomeric RIA and RIB may be derived by either processing of PrpRI or truncated transcription of the gene. were isolated which differed from RIA and RIB by two amino acid changes within the first 20 amino acids from the N-terminus, $\mathrm{Gln}_{8} \rightarrow \mathrm{Glu}_{8}$ and $\mathrm{Ala}_{17} \rightarrow \mathrm{Pro}_{17}$, as shown in Fig. 1.

A spontaneously arising mutant with weakly pigmenting colony forms was isolated from cultures of $P$. gingivalis W50 grown in the chemostat by McKee et al. (1988). This mutant was named W50/BE1 due to the beige colour of the colonies after $21 \mathrm{~d}$, in contrast to the wildtype, which pigments black by $7 \mathrm{~d}$. The wild-type and the mutant were tested for virulence in a mouse model of pathogenicity based on the method of van Steenbergen et al. (1982). P. gingivalis W50 was injected subcutaneously into the mouse at an infective dose of $1 \times 10^{9}$ viable cells, which caused a spreading inflammation characterized by necrosis of tissues from the epidermis to the abdominal muscle layers, localized abscess formation, diffuse accumulation of polymorphonuclear leucocytes, oedema and death of all the mice. W50/BE1 killed no animals and caused either a mild inflammatory reaction or microscopic foci of dermal inflammation and remained avirulent at all infective doses tested (McKee et al., 1988).

W50/BE1 lacked gelatinase, collagenase and dipeptidyl aminopeptidase activities compared to the parent strain, and had reduced hydrophobicity, haemagglutinating activity, fimbriation and extracellular vesicle production (Shah et al., 1989). In particular, the level of extracellular Arg-x protease activity in W50/BE1 was significantly lower than in the parent strain P. gingivalis W50. These enzymes are considered to play an important role in virulence, supported by evidence from several studies on spontaneously arising and transposon-induced mutants lacking Arg-x activity. Kesavalu et al. (1996) showed that $P$. gingivalis W50 treated with an active-site inhibitor ( $N \alpha-p$-tosyl-L-lysine chloromethyl ketone; TLCK) specific for the Arg-x and Lys-x proteases prior to subcutaneous injection into the mouse failed to give the necrotic reaction observed when untreated cells were injected. In the same study, the protease-deficient mutant NG4B19 derived from $P$. gingivalis strain 3079.03 was found to be completely avirulent. Similarly, mutant V2296 derived from insertional inactivation of the prtH gene encoding Arg-x protease activity from $P$. gingivalis strain W83 also showed a corresponding reduction in virulence in the mouse model (Fletcher et al., 1995).

The aim of this study was to isolate and characterize the enzymes from W50/BE1 to determine whether the reduced level of activity in the mutant represents reduced synthesis of all of the wild-type enzymes, or production of differing amounts of the three forms. This information will lead to a better understanding of the role of these proteases in the virulence of the organism.

\section{METHODS}

To distinguish the proteases of $P$. gingivalis W50 from those of the mutant $P$. gingivalis W50/BE1, enzymes derived from the mutant will be given the suffix '/BE'.

Materials. DEAE-Sephacel and Sephacryl S-200 HR were obtained from Pharmacia Biotechnology. L-Arg- $4 \%$ beaded agarose, DL-BRpNA, L-BRpNA and leupeptin were purchased from Sigma or Bachem Feinchemikalien. Zwittergent 3-14 detergent and DNS-EGRCK were obtained from Calbiochem Novabiochem (UK). All other chemicals and reagents were the purest grades available from Sigma or BDH.

Bacterial strains and growth conditions. $P$. gingivalis W50/ BE1 was obtained from P. Marsh (PHLS, Porton Down, UK). Strains were maintained on blood agar plates $[2.5 \%, \mathrm{v} / \mathrm{v}$, horse blood (TCS) added to $4 \%, w / v$, blood agar base no. 2 (Oxoid) in distilled water] at $37^{\circ} \mathrm{C}$ in an anaerobic cabinet (Don Whitley Scientific) equilibrated in nitrogen/hydrogen/ carbon dioxide (80:10:10, by vol.). Batch culture was carried out in $3.7 \%(\mathrm{w} / \mathrm{v})$ brain heart infusion broth (Oxoid) containing $0.0005 \%(\mathrm{w} / \mathrm{v})$ haemin for $6 \mathrm{~d}$ in the anaerobic cabinet.

Enzyme assays. Measurement of Arg-specific enzyme activity was carried out as described by Rangarajan et al. (1997a). In general, $0.3-0.5 \mu \mathrm{g}$ enzyme was used per assay. CAPS, CHES, 
HEPES, MES, MOPS and Tris/ $\mathrm{HCl}$ were used as buffers in the determination of $\mathrm{pH}$ optima. The $\mathrm{pH}$ of the buffers was adjusted at room temperature; the actual $\mathrm{pH}$ at $30^{\circ} \mathrm{C}$ was calculated from the heats of ionization of the buffers: $\Delta \mathrm{pH}$ per ${ }^{\circ} \mathrm{C}=-0.011$ for MES, -0.013 for MOPS, -0.014 for HEPES, -0.028 for Tris/HCl (Good et al., 1966), -0.011 for CHES and -0.012 for CAPS (Dawson et al., 1986). The buffers were then adjusted to an ionic strength of $12 \mathrm{mS}$ by addition of $\mathrm{NaCl}$. To avoid affecting the $\mathrm{pH}$ for measurement of the $\mathrm{pH}$ optimum, DTT was used as the reducing agent in the assay buffer in place of cysteine $(\mathrm{HCl})$. One unit of enzyme activity is defined as that amount of enzyme which liberates $1 \mu \mathrm{mol} p$ nitroaniline $\min ^{-1}$ at $30^{\circ} \mathrm{C}$.

Values of maximum velocity, $V_{\max }$ (units $\mathrm{mg}^{-1}$ ), and apparent $K_{\mathrm{m}}(\mu \mathrm{M})$ were derived by non-linear regression analysis of the data using the ENZFITTER Data Analysis program (Biosoft) with $2 \cdot 5-250 \mu \mathrm{M}$ L-BRpNA at $30^{\circ} \mathrm{C} \pm 0 \cdot 1{ }^{\circ} \mathrm{C}$.

Determination of protein concentrations. Protein concentrations were determined by $A_{280}$ and $A_{260}$ measurements (Dawson et al., 1986) in a Kontron Uvicon 930 spectrophotometer. Protein concentration was then calculated according to the formula $\left[1.55\left(A_{280}\right)-0.76\left(A_{260}\right)\right]$.

Purification of Arg-specific proteases. $P$. gingivalis W50/BE1 $6 \mathrm{~d}$ culture $(6-8 \mathrm{l})$ was centrifuged and the supernatant used as the source of the Arg-specific proteases. Enzymes were purified using the techniques developed for the wild-type $P$. gingivalis W50 as described by Rangarajan et al. (1997a). Following ammonium sulphate precipitation of the culture supernatant, Arg-specific activity of $P$. gingivalis W50 is separated into two fractions, soluble $(\mathrm{S})$ and pellet $(\mathrm{P})$, by differential detergent solubilization of the ammonium sulphate pellet. Fraction $\mathrm{S}$ contains RI and RIA, which are soluble in low-detergent buffer $(0.0055 \%)$ and are separated from each other by Argagarose affinity chromatography. Fraction P contains RIB, which is membrane/vesicle-associated and requires highdetergent buffer $(0.05 \%)$ for solubilization.

SDSPAGE of purified proteins. Protein samples were run on $12.5 \%$ polyacrylamide slab gels $(10 \mathrm{~cm} \times 7 \mathrm{~cm} \times 0.15 \mathrm{~cm})$ containing SDS (Laemmli, 1970) at $5^{\circ} \mathrm{C}$. In general, $20 \mu \mathrm{g}$ protein was used per sample, which in each case was first treated with an equal volume of $1 \mathrm{mM}$ leupeptin at $22^{\circ} \mathrm{C}$ for $20 \mathrm{~min}$ and heated at $100^{\circ} \mathrm{C}$ for $5 \mathrm{~min}$ to inhibit autolytic activity. Samples containing high salt were then dialysed against $5 \%\langle\mathrm{v} / \mathrm{v}\rangle$ acetic acid $/ 0.0055 \%$ Zwittergent and dried in vacuo before being treated with SDS sample buffer. Proteins were transferred to nitrocellulose membranes in a CAPS buffer system (10 mM CAPS, $\mathrm{pH} 11 ; 10 \%, \mathrm{v} / \mathrm{v}$, methanol) at a constant current of $400 \mathrm{~mA}$ for $30 \mathrm{~min}$. After blotting, the membranes were blocked in $5 \%(\mathrm{w} / \mathrm{v}) \mathrm{BSA}$ and incubated overnight in primary antibody in $1 \%(\mathrm{w} / \mathrm{v})$ BSA. Antibody binding was detected using horseradish-peroxidaseconjugated anti-species immunoglobulins and diaminobenzidine $(0.05 \%, \mathrm{w} / \mathrm{v})$.

$\mathbf{N}$-terminal sequencing. Proteins were transferred to PVDF Immobilon membranes (Millipore) after SDS-PAGE. Nterminal amino acid sequencing was carried out at the Haemostasis Research Group, Royal Postgraduate Medical School, London, UK.

Active-site titration. Active-site titration was used to determine the proportion of active protease present in the purified preparations, based on the method of Potempa et al. (1997). A series of standard solutions of the fluorescent activesite inhibitor DNS-EGRCK at concentrations of $0 \cdot 1-1 \mu \mathrm{M}$ was made in $1 \mathrm{mM} \mathrm{HCl}$. Enzyme $\left(0 \cdot 2-0 \cdot 6 \mathrm{mg} \mathrm{m}^{-1}\right)$ was incubated in $0.125 \mathrm{M}$ Tris $/ \mathrm{HCl} / 12.5 \mathrm{mM} \mathrm{CaCl} / 12.5 \mathrm{mM}$ L-cysteine, $\mathrm{pH} 8.0$, at $22^{\circ} \mathrm{C}$ for $30 \mathrm{~min}$ to activate the protease. Aliquots $(20 \mu \mathrm{l})$ of activated protease were measured into $1.5 \mathrm{ml}$ disposable cuvettes (Elkay Products) and $20 \mu \mathrm{l}$ of each standard solution of inhibitor was added. The solutions were mixed thoroughly and incubated for $30 \mathrm{~min}$ at $30^{\circ} \mathrm{C}$. The reaction was stopped by the addition of $0.8 \mathrm{ml}$ of assay buffer maintained at $30^{\circ} \mathrm{C}$ and enzyme activity remaining was measured by the addition of $0.2 \mathrm{ml} 500 \mathrm{mM}$ DL-BRpNA substrate. All assays were performed in duplicate.

\section{RESULTS}

\section{Arg-x enzyme activity of $\boldsymbol{P}$. gingivalis W50/BE1}

Total Arg-x specific enzyme activity in the $6 \mathrm{~d}$ culture was $0.16 \mathrm{U}$ (ml culture) $)^{-1}$ as compared with $0.48 \mathrm{U}(\mathrm{ml}$ W50 culture $)^{-1}$. Arg-x specific enzyme activity in the $6 \mathrm{~d}$ culture supernatant of $P$. gingivalis W50/BE1 was approximately $25-30 \%$ of the activity of the parent strain $[0 \cdot 11 \mathrm{U} \text { (ml W50/BE1 culture })^{-1}$ as compared with $0.37 \mathrm{U}$ (ml W50 culture $)^{-1}$. The mutant also showed a corresponding reduction in the Lys-x specific activity to approximately $20 \%$ of the level in the parent strain. Details of purification of the Arg-specific enzymes from the culture supernatant are shown in Table 1. Greater than $95 \%$ of the Arg-x enzyme activity was precipitated from the culture supernatant using $85 \%$ ammonium sulphate. Approximately $70 \%$ of enzyme activity could be solubilized from the ammonium sulphate pellet using low-detergent $(0 \cdot 0055 \%)$ buffer. In keeping with the nomenclature used for the parent strain enzymes, the portion of the enzyme activity in this soluble fraction which was bound on the Arg affinity chromatography resin was designated $\mathrm{RI} / \mathrm{BE}$ and activity not retained was referred to as RIA/BE. RI/BE was isolated with relatively high purity due to the specificity of the affinity chromatography step. In the residual ammonium sulphate pellet, a further $14 \%$ of total enzyme activity could be solubilized using highdetergent $(0.05 \%)$ buffer. This was designated RIB/BE. The bulk of the remaining activity could only be extracted with large volumes of high-detergent buffer following repeated extractions and was therefore not routinely attempted. $\mathrm{RIA} / \mathrm{BE}$ and $\mathrm{RIB} / \mathrm{BE}$ required several ion-exchange chromatography steps to achieve pure enzyme. This is reflected in the low values of yield and specific activity (Table 1) compared to enzymes from $P$. gingivalis W50, which suggests that some inactivation could have occurred (see later).

\section{Genetic origin of purified proteins}

Purity of the three enzymes was assessed by SDS-PAGE (Fig. 2). Comparison of RI from the wild-type versus RI/BE showed major differences. Whereas RI gave only one band on SDS-PAGE, which contained both $\alpha$ - and $\beta$ subunits (Rangarajan et al., 1997a), RI/BE showed the presence of three strong bands of approximately 54, 36 and $30 \mathrm{kDa}$. N-terminal amino acid sequencing of these bands indicated that the $54 \mathrm{kDa}$ protein corresponds to the $\alpha$-catalytic domain, the $36 \mathrm{kDa}$ protein represents a 
Table 1. Purification and yields of the three forms of Arg-x protease from $P$. gingivalis W50/BE1

For experimental details see text. The values are from 71 culture supernatant. Bold typeface indicates data for pure protease samples.

\begin{tabular}{|c|c|c|c|c|c|c|}
\hline \multirow[t]{2}{*}{ Purification step } & \multirow{2}{*}{$\begin{array}{c}\text { Total } \\
\text { activity } \\
(\mathbf{U})\end{array}$} & \multirow{2}{*}{$\begin{array}{c}\text { Total } \\
\text { protein } \\
(\mathrm{mg})\end{array}$} & \multirow{2}{*}{$\begin{array}{l}\text { Specific activity } \\
\quad\left(\mathrm{U} \mathrm{mg}^{-1}\right)\end{array}$} & \multicolumn{2}{|c|}{ Yield $(\%)$} & \multirow{2}{*}{$\begin{array}{l}\text { Purification } \\
\text { (-fold) }\end{array}$} \\
\hline & & & & Step & Total & \\
\hline 1. Culture supernatant & 1245 & 117600 & $0 \cdot 010$ & 100 & 100 & 1 \\
\hline 2. Ammonium sulphate $(85 \%)$ & 1186 & 98090 & $0 \cdot 012$ & 95 & 95 & $1 \cdot 2$ \\
\hline 3. Soluble fraction $(\mathrm{S})$ & 807 & 5580 & $0 \cdot 150$ & 68 & 65 & 15 \\
\hline 3.1 Affinity chromatography fraction & 165 & $12 \cdot 1$ & $13 \cdot 640$ & 20 & 13 & $\underline{1364}$ \\
\hline S-B (bound) & & & & & & \\
\hline 3.2 DEAE-Sephacel chromatography & 176 & $28 \cdot 4$ & $6 \cdot 190$ & 22 & 14 & $\underline{619}$ \\
\hline of S-U (unbound) $\quad \underline{\text { RIIA }}$ /BE & & & & & & \\
\hline 4. Pellet fraction $(\mathrm{P})$ & 161 & 1364 & $0 \cdot 120$ & 14 & 13 & 12 \\
\hline $\begin{array}{l}\text { 4.1 Affinity chromatography fraction } \\
\text { P-U (unbound) }\end{array}$ & 148 & 1064 & $0 \cdot 140$ & 92 & 12 & 14 \\
\hline 4.2 DEAE-Sephacel chromatography & 28 & $15 \cdot 6$ & $1 \cdot 800$ & 17 & $2 \cdot 3$ & $\underline{180}$ \\
\hline of P-U $\quad \underline{\text { RIIA } / B E}$ & & & & & & \\
\hline
\end{tabular}

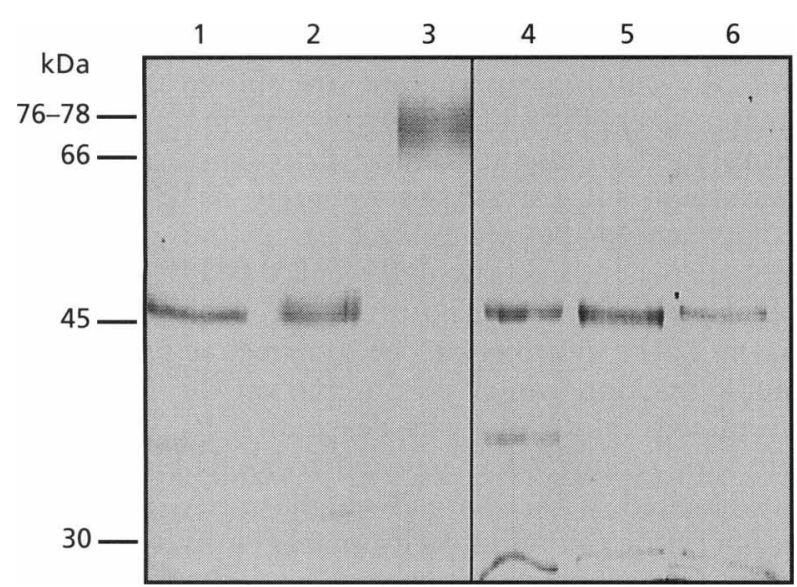

Fig. 2. SDS-PAGE of Arg-specific proteases from $P$. gingivalis W50 and W50/BE1. Pure RI, RIA, RIB, RI/BE, RIIA $5 / B E$ and RIIAV/BE were treated with $1 \mathrm{mM}$ leupeptin to inhibit protease activity and subjected to SDS-PAGE in $12.5 \%$ acrylamide gels. The molecular masses of marker proteins are indicated alongside the gel. Lanes: 1, RI; 2, RIA; 3, RIB; 4, RI/BE; 5 , RIIA $/ B E ; 6$, RIIAV/BE. Gels were stained for protein with Coomassie brilliant blue R250.

C-terminally truncated $\beta$-domain and the $30 \mathrm{kDa}$ protein is derived from the $\gamma$-region of the PrpRI protein precursor (Table 2). This is shown in Fig. 3, in which the internal processing sites within the $\beta$ - and $\gamma$-regions are indicated. Cleavage of the peptide bond between the pro- and $\alpha$-regions, $\operatorname{Arg}_{227}-\mathrm{Tyr}_{228}$, and the bond between the $\alpha$ - and $\beta$-regions, $\operatorname{Arg}_{719}-\operatorname{Ser}_{720}$, generates the $\alpha$ catalytic domain which is unaltered in the enzymes from W50 and W50/BE1. The putative processing site between the $\beta$ - and $\gamma$-regions, $\operatorname{Arg}_{1262}-\mathrm{Phe}_{1263}$, would generate the $\sim 58 \mathrm{kDa} \beta$-adhesin domain seen in $\mathrm{RI}$ from the wild-type strain. However, the size of the $\beta$ domain seen in RI/BE suggests that processing of the
PrpRI precursor may occur at $\operatorname{Arg}_{1138}-\mathrm{Ala}_{1139}$, giving rise to the $\sim 36 \mathrm{kDa}$ peptide $\left(\operatorname{Ser}_{720}-\mathrm{Arg}_{1138}\right)$. Hydrolysis of $\mathrm{Arg}_{1431}-\mathrm{Ala}_{1432}$ within the $\gamma$-region would release a $\sim 30 \mathrm{kDa}$ C-terminal peptide. However, the intervening fragment, $\mathrm{Ala}_{1139}-\mathrm{Arg}_{1431}$, was not observed on SDSPAGE of RI/BE. It is possible that the 'missing' $\mathrm{Ala}_{1139}-\mathrm{Arg}_{1431}$ peptide has been processed into smaller fragments which are not detected on either $12.5 \%$ SDSPAGE or on SDS-gradient gels. Samples of RI/BE which were electroblotted onto PVDF membranes after SDSPAGE for N-terminal amino acid sequencing also showed the presence of two minor bands $(<2 \%$ intensity of all Coomassie-stained bands) of $\sim 78 \mathrm{kDa}$ and $\sim 57 \mathrm{kDa}$. N-terminal amino acid sequence analysis revealed the same $\mathrm{N}$-terminus as the $36 \mathrm{kDa}$ truncated $\beta$ region (SGQAE ...; see Table 2). However, the size of these fragments indicates that they probably encompass all of the $\beta$-region and part of the $\gamma$-region of PrpRI (Aduse-Opoku et al., 1995), i.e. Ser $_{720}-\operatorname{Arg}_{1431}$. These large fragments have never been observed in preparations of RI from $P$. gingivalis W50. In all previous work (Rangarajan et al., 1997b; Pavloff et al., 1995), the largest peptide from the $\beta$ - and $\gamma$-regions of PrpRI has been the $\beta$-adhesin domain of RI from $P$. gingivalis W50. It is possible that the $\sim 78 \mathrm{kDa}$ and $\sim 57 \mathrm{kDa}$ domains co-purify with $\mathrm{RI} / \mathrm{BE}$ during affinity chromatography on Arg-agarose columns.

RIA/BE gave two protein bands on SDS-PAGE corresponding to $\sim 54 \mathrm{kDa}$ and $\sim 26 \mathrm{kDa}$, which differs from the parent RIA, which gives only a single band of $\sim 54 \mathrm{kDa}$. N-terminal amino acid sequencing (Table 2) revealed that the $\sim 54 \mathrm{kDa}$ peptide was derived from prR2 since it contained the characteristic Glu residue at position 8 and Pro residue at position 17 (versus Gln $_{8}$ and $\mathrm{Ala}_{17}$ in $p r p R 1$-derived enzymes). Furthermore, the $\mathrm{N}$-terminal amino acid sequence of the $\sim 26 \mathrm{kDa}$ peptide (GRNPQ...) is located in the pro-region of $p r R 2$ [Rangarajan et al., 1997b; accession no. AF007124 
Table 2. N-terminal amino acid sequence of $P$. gingivalis W50/BE1 Arg-specific enzymes

\begin{tabular}{|lcl|}
\hline Enzyme & $\begin{array}{c}\text { Molecular } \\
\text { mass }(\mathbf{k D a})\end{array}$ & \multicolumn{1}{c|}{$\begin{array}{c}\text { N-terminal amino acid } \\
\text { sequence* }\end{array}$} \\
\hline RI/BE & 54 & YTPVEEK $\ldots$ \\
& 36 & SGQAE ... \\
& 30 & ANEA ... \\
RIIA $^{\mathrm{s}} / \mathrm{BE}$ & 54 & YTPVEEKENGRMIVIVPKKY ... \\
& 26 & GRNPQVRLLSAE ... \\
RIIA $^{\mathrm{v}} / \mathrm{BE}$ & 54 & YTPVEEKENGRMIVIVPKKY ... \\
& 26 & GRNPQVRLL ... \\
\hline
\end{tabular}

"Amino acid residues which differ from those present in corresponding enzymes from $P$. gingivalis W50 are indicated in bold.

(a)

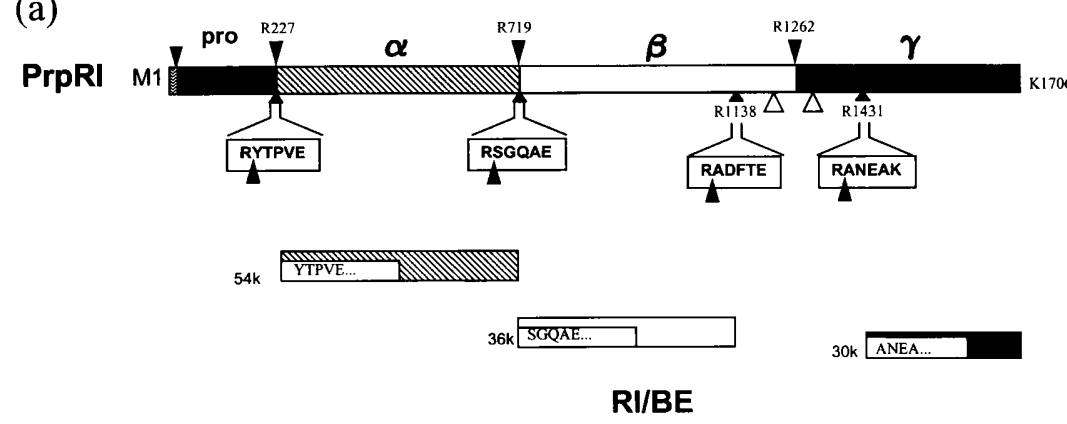

(b)
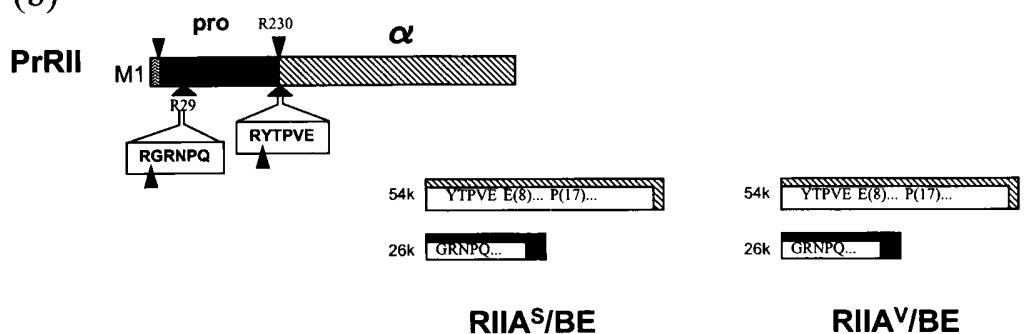

RIIAS/BE

RIIAV/BE

Fig. 3. Generation of the three forms of Arg-specific proteases in $P$. gingivalis W50/BE1. The organization of PrpRI and PrRII are as in Fig. 1. (a) Arrowheads above PrpRI indicate the proteolytic processing sites required to generate the heterodimer of RI. Arrowheads below PrpRI indicate putative processing sites required to generate the multimer form of RI/BE. Open arrowheads indicate the additional processing sites proposed by Pavloff et al. (1995) which generate a multimeric, nonstoichiometric complex of polypeptides which in association with the $\alpha$-domain generates HMG. (b) Arrowheads above PrRII indicate the protease processing site required to generate RIIA and RIIB. Arrowheads below PrRII indicate processing sites required to generate $R I I A^{S} / B E$ and RIIAV/BE.
(N. Slakeski and others, complete cds)] and would be generated by processing at $\mathrm{Arg}_{29}-\mathrm{Gly}_{30}$ and $\mathrm{Arg}_{230}-$ $\mathrm{Tyr}_{231}$, which would release a peptide fragment of 201 residues (Fig. 4).

In the case of the membrane/vesicle-bound enzyme, we did not observe a highly modified form equivalent to RIB from the parent strain. Instead, RIB/BE gave two bands of $\sim 54 \mathrm{kDa}$ and $\sim 26 \mathrm{kDa}$ on SDS-PAGE as we had observed for RIA/BE. The N-terminal amino acid sequences of the $\sim 54$ and $\sim 26 \mathrm{kDa}$ bands from $\mathrm{RIB} / \mathrm{BE}$ were identical to the $\mathrm{N}$-terminal sequences obtained for RIA/BE, indicating that RIB/BE was also derived from $p r R 2$. Throughout the remainder of the manuscript we will therefore refer to these $p r R 2$-derived enzymes in W50/BE1 as $\mathrm{RIIA}^{\mathrm{S}} / \mathrm{BE}$ (soluble) and $\mathrm{RIIA}^{\mathrm{v}} / \mathrm{BE}$ (vesicle-bound) to indicate that they are derived from prR2 (Fig. 3) and are probably the same isoform with different extracellular locations.

\section{Antibody reactivity of purified proteins}

Western blotting with antibodies raised either to $P$. gingivalis W50 whole cells, the $\beta$-region of $P$. gingivalis W50 or $P$. gingivalis W50 LPS was carried out as a means of comparing W50/BE1 enzymes with those from W50.

The anti-whole-cell antibody recognized all major components of the protein samples apart from the $\sim 30 \mathrm{kDa}$ fragment of $\mathrm{RI} / \mathrm{BE}$ and the $\sim 26 \mathrm{kDa}$ propeptide domain of RIIA ${ }^{\mathrm{S}} / \mathrm{BE}$ and $\mathrm{RIIA}^{\mathrm{V}} / \mathrm{BE}$ (Fig. 5a). Antibody 1A1, a monoclonal recognizing the $\beta$-region of RI, gave a positive reaction with the $\sim 78, \sim 57$, $\sim 54$ and $\sim 36 \mathrm{kDa}$ bands $\left(\operatorname{Ser}_{720}-\operatorname{Arg}_{1138}\right)$ of $\mathrm{RI} / \mathrm{BE}$, confirming that these polypeptides contain $\mathrm{Gly}_{907}$ $\mathrm{Thr}_{931}$ recognized by the antibody (Curtis et al., 1996) (Fig. 5b). Antibody 1B5, a monoclonal which recognizes $P$. gingivalis W50 LPS (unpublished observation) and which reacts with both RIA and RIB, failed to recognize 
PrtR2 1 MKKNFSRIVSIVAFSSLLGGMAFAQPAERGRNPQVRLL.SAEQSMSKVQF 49

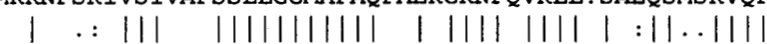

PrPRI 1 .MKNLNKFVS IALCSSLLGGMAFAQOTELGRNPNVRLLESTQOSVTKVQF 49

PrtR2 50 RMDNLQFTGVQTSKGVAQVPTFTEGVNISEKGTPILPILSRSLAVSETRA 99

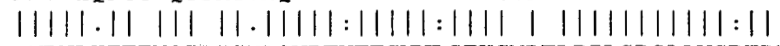

PrPRI 50 RMDNLKFTEVQTPKGMAQVPTYTEGVNLSEKGMPTLPILSRSLAVSDTRE 99

PrtR2 100 MKVEVVSSKFIEKKDVLIAPSKGVISRAENPDQIPYVYGQSSYNEDKFFPG 149 \|\|\|\|\|\|\|\|$\|\|\|\|.\left\|.|||| ..\left|\|\|\|.|| . .\|_{\|}\|\|\right.\right.$

PrPRI 100 MKVEVVSSKFIEKKNVLIAPSKGMIMRNEDPKKI PYVYGKSYSONKFFPG 149

PrtR2 150 EIATLSDPFILRDVRGQVVNFAPLQYNPVTKTLRIYTEIVVAVSETAEAG 199

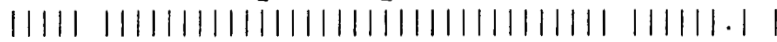

PrPRI 150 EIATLDDPFILRDVRGQVVNFAPLQYNPVTKTLRIYTEITVAVSETSEQG 199

PITR2 200 QNTISLVKNSTFTGFEDIYKSVFMNYEATRYTPVEEKENGRMIVIVPKKY 249

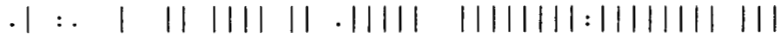

PrPRI 200 KNILN. KKGTFAGFEDTYKRMFMNYEPGRYTPVEEKONGRMIVIVAKKY 247
Fig. 4. Alignment of N-terminal amino acid sequences of PrtR2 and PrpRI. The $\sim 26 \mathrm{kDa}$ peptide of RIIA $/ B E$ and $R I I A^{V} / B E$ is generated by cleavage of the bonds at $\mathrm{Arg}_{29}-\mathrm{Gly}_{30}$ and $\mathrm{Arg}_{230}-\mathrm{Tyr}_{231}$. The fragment is derived from the prR2 locus (analogous to prtR2), indicated by the characteristic $\mathrm{Glu}_{8}$ and $\mathrm{PrO}_{17}$ (versus $\mathrm{Gln}_{8}$ and $\mathrm{Ala}_{17}$ in prpR1derived enzymes). (a)

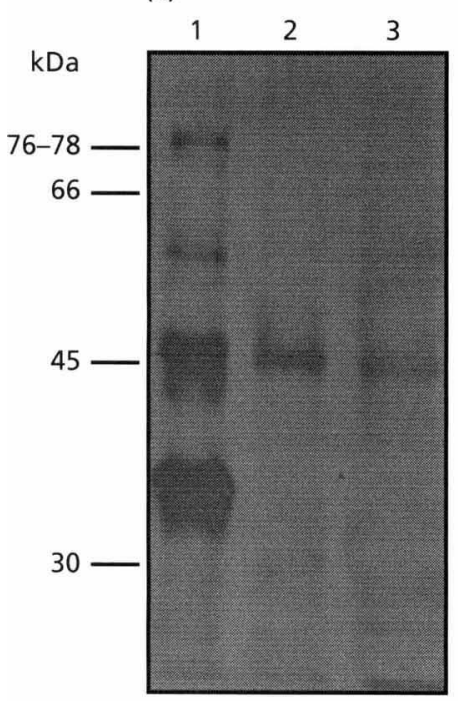

(b)

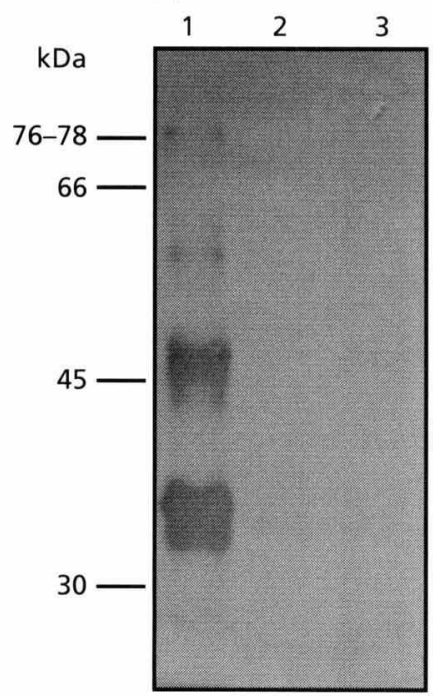

(c)

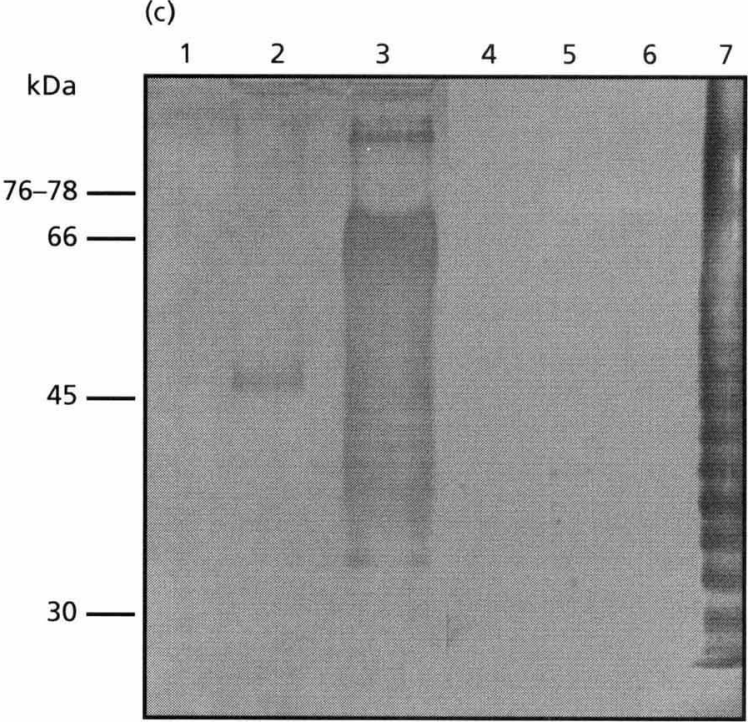

Fig. 5. Western blot analysis of Arg-specific proteases of $P$. gingivalis W50/BE1. Pure protease samples were immunoblotted onto nitrocellulose membranes and probed with a polyclonal antibody raised to $P$. gingivalis W50 whole cells $(\alpha-W c)$, and $\mathrm{mAbs}$ raised to $P$. gingivalis W50 RI $\beta$-chain (1A1) and $P$. gingivalis W50 LPS (1B5). Antibody binding Was detected using horseradish-peroxidase-conjugated anti-species immunoglobulins and diaminobenzidine. The molecular masses of marker proteins are indicated alongside the blots. (a) Lanes 1-3, antibody $\alpha-W C$ against RI/BE, RIIA $/ B E$ and RIIA $/ B E$, respectively. (b) Lanes 1-3, antibody $1 A 1$ against RI/BE, RIIA $/ B E$ and RIIAV/BE, respectively. (c) Lanes 1-7, antibody $1 B 5$ against RI, RIA, RIB, RI/BE, RIIAS/BE, RIIAV/BE and $P$. gingivalis W50 LPS, respectively.

$\mathrm{RIIA}^{\mathrm{S}} / \mathrm{BE}$ or $\mathrm{RIIA}^{\mathrm{V}} / \mathrm{BE}$, indicating that the proteases from W50/BE1 lack glycan modifications (Fig. 5c).

\section{Enzymology}

Enzyme kinetic studies were carried out to establish the similarity of the proteases from the mutant to the proteases from the wild-type (Table 3). Optimum enzyme activity was obtained when cysteine $(10 \mathrm{mM})$ was used in the assay buffer. The $\mathrm{pH}$ optimum for both the mutant and wild-type enzymes was 7.9-8.1, measured in the presence of $10 \mathrm{mM}$ DTT. However, $\mathrm{RI} / \mathrm{BE}$ appeared to have a broader $\mathrm{\rho H}$ optimum for $\mathrm{L}^{-}$ BRpNA activity. $K_{m}$ and $V_{\max }$ wer: measured at $\mathrm{pH} 8 \cdot 1$ in the presence of $10 \mathrm{mM}$ L-cysteine as the reducing agent: the $K_{\mathrm{m}}$ of the mutant enzymes (9-13 $\mu \mathrm{M}$ using the chromogenic substrate L-BRpNA) was found to be of the same order of magnitude as the $K_{m}$ for the wild-type enzymes whereas the $V_{\max }$ of RIIA $^{\mathrm{S}} / \mathrm{BE}$ and RIIA ${ }^{\mathrm{V}} / \mathrm{BE}$ was approximately three- to fivefold lower than that of the corresponding enzymes from W50 and W501 (Table $3)$. Active-site titration of the enzymes indicated that the percentage of active enzyme in the purified preparations from W50/BE1 was only $28 \%$ for RIIA $/ \mathrm{BE}$ and $20 \%$ for RIIA ${ }^{\mathrm{V}} / \mathrm{BE}$, which could account for the low $V_{\max }$ compared to enzymes from $P$. gingivalis W50. This inactivation could be a result of the number of steps needed to isolate the pure enzymes. Protease RI/BE, 
Table 3. Kinetic constants for Arg-specific protease activity from $P$. gingivalis W50 and W50/BE 1

\begin{tabular}{|llccc|}
\hline Strain & Enzyme & $\begin{array}{c}\mathrm{pH} \\
\text { optimum }\end{array}$ & $\boldsymbol{K}_{\mathrm{m}}\langle\boldsymbol{\mu M} ; \pm \mathrm{SE})^{*}$ & $\boldsymbol{V}_{\max }\left(\mathbf{U ~ m g}^{-1} ; \pm \mathrm{SE}\right)^{*}$ \\
\hline W50 & RI & $7 \cdot 9-8 \cdot 1$ & $6 \pm 0 \cdot 90$ & $11 \pm 0 \cdot 05$ \\
& RIA & $7 \cdot 9-8 \cdot 1$ & $10 \pm 1 \cdot 30$ & $17 \pm 0 \cdot 13$ \\
W501 (prpR1 isogenic & RIB & $7 \cdot 9-8 \cdot 1$ & $14 \pm 1 \cdot 25$ & $17 \pm 0 \cdot 08$ \\
mutant) & RIIA & $7 \cdot 9-8 \cdot 1$ & $4 \pm 1 \cdot 10$ & $17 \pm 0 \cdot 09$ \\
W50/BE1 & RIIB & $7 \cdot 9-8 \cdot 1$ & $5 \pm 1 \cdot 40$ & $12 \pm 0 \cdot 06$ \\
& RI/BE & $8 \cdot 0-8 \cdot 6$ & $9 \pm 1 \cdot 25$ & $13 \pm 0 \cdot 13$ \\
& RIIA $/$ BE & $7 \cdot 9-8 \cdot 1$ & $13 \pm 1 \cdot 57$ & $6 \pm 0 \cdot 16$ \\
& RIIA $^{\mathrm{v}} / \mathrm{BE}$ & $7 \cdot 9-8 \cdot 1$ & $13 \pm 1 \cdot 13$ & $3 \pm 0 \cdot 07$ \\
\hline
\end{tabular}

${ }^{*} K_{\mathrm{m}}$ and $V_{\max }$ were measured at $30^{\circ} \mathrm{C}$ in $0 \cdot 1 \mathrm{M}$ Tris $/ \mathrm{HCl} / 10 \mathrm{mM} \mathrm{Ca}^{2+} / 10 \mathrm{mM}$ cysteine, $\mathrm{pH} 8 \cdot 1$, using L-BRpNA as the chromogenic substrate.

which required fewer purification steps, contained $73 \%$ of active enzyme and the $V_{\max }$ value was comparable to that of RI. This suggests that the presence of extra polypeptides in RI/BE does not affect protease activity.

\section{DISCUSSION}

The Arg-specific proteases of $P$. gingivalis are thought to be important virulence determinants of the organism. This has been supported by studies using spontaneously occurring and transposon-induced protease-deficient mutants which demonstrate reduced virulence (Kesavalu et al., 1996; Fletcher et al., 1995). The present work confirms previous reports of reduced Arg-specific activity in the avirulent $P$. gingivalis W50/BE1 mutant. Recent progress in determining the genetic origin of the Arg-specific proteases from $P$. gingivalis W50 has allowed us to investigate whether reduced activity in W50/BE1 reflects reduced levels of all the isoforms or specific reduction of individual components.

Purification of the Arg-specific activity yielded three enzymes, RI/BE, RIIA ${ }^{\mathrm{s}} / \mathrm{BE}$ and $\mathrm{RIIA}{ }^{\mathrm{v}} / \mathrm{BE}$, which differ in subunit organization and N-terminal amino acid sequence from the equivalent enzymes from the parent strain. There was a decrease in extracellular proteases derived from the prpR1 locus - RI/BE accounted for $13 \%$ of the total Arg-specific enzyme activity (compared with $20 \%$ in the parent strain W50) and RIA and RIB were absent. Activity was partially compensated by expression of $p r R 2$ products $\mathrm{RIIA}^{\mathrm{S}} / \mathrm{BE}$ and $\mathrm{RIIA}^{\mathrm{V}} / \mathrm{BE}$. Therefore, there is an overall reduction in activity in the mutant as well as different synthesis/distribution of $p r p R 1$ and $p r R 2$ products.

In addition to the altered distribution of the prpR 1 and $p r R 2$ products in W50/BE1, it appears that the proteases may be differently processed relative to the parent strain. $\mathrm{RI} / \mathrm{BE}$ is composed of three peptide chains of approximately 54,36 and $30 \mathrm{kDa}$ in contrast to the $\alpha \beta$ heterodimer structure of RI from W50. RI/BE is similar to a multimeric high-molecular-mass complex termed high-molecular-mass gingipain (HMG), which is derived from a homologous gene, $r g p-1$, in $P$. gingivalis strain HG66 (Potempa et al., 1997; Pavloff et al., 1995). rgp-1 encodes a polyprotein of 1704 amino acids which is processed to give peptides of $54,44,27,17$ and $15 \mathrm{kDa}$. The $54 \mathrm{kDa}$ peptide is analogous to the $54 \mathrm{kDa} \alpha$ catalytic domain of $\mathrm{RI} / \mathrm{BE}$, the $44 \mathrm{kDa}$ peptide has the same $\mathrm{N}$-terminal amino acid sequence as the $36 \mathrm{kDa} \beta$ adhesin domain of $\mathrm{RI} / \mathrm{BE}$, and the $27 \mathrm{kDa}$ fragment is derived from the $\gamma$-region and is analogous to the $30 \mathrm{kDa}$ fragment from RI/BE. However, the 15 and $17 \mathrm{kDa}$ peptides, generated by cleavage between $\operatorname{Arg}_{1138}$ $\mathrm{Ala}_{1139}, \mathrm{Lys}_{1273}-\mathrm{Pro}_{1274}$ and $\mathrm{Arg}_{1431}-\mathrm{Ala}_{1432}$, respectively, are not seen on SDS-PAGE gels of RI/BE. This region contains at least five Arg residues, and it is possible that the peptides undergo autolytic degradation into smaller peptide fragments which cannot be detected on SDS-PAGE gels.

There may be a number of explanations for the observed differences in the subunit organization of RI purified from $P$. gingivalis W50 versus W50/BE1. It has already been established that there are a range of phenotypic differences between W50 and W50/BE1, including cell surface properties, proteolytic enzyme production and haemagglutination (McKee et al., 1988). It is plausible that these differences may also include alterations to the processing/export machinery of the RI protease which leads to the generation of a different subunit organization of this enzyme from W50/BE1. Alternatively, the altered subunit organization of W50/BE1 RI may simply reflect differences in the proteolytic degradation of the enzyme in stationary-phase culture compared to the parent strain, since the overall proteolytic activity in these culture supernatants is markedly different. Some support for this proposal comes from the studies of Smalley \& Birss (1991), which demonstrated that high-molecular-mass forms of extracellular Argspecific enzyme are present in exponential-phase cultures of W50/BE1 and these are reduced in cultures older than $24 \mathrm{~h}$. The purifications in the present report were deliberately performed on late-stationary-phase cultures to maximize the levels of enzyme in the culture supernatant and it is possible that this has accentuated a differential effect on extracellular degradation. A similar 
explanation may account for the inconsistencies in the literature on the subunit organization of this protease isolated from different $P$. gingivalis strains (Pavloff $e t$ al., 1995; Rangarajan et al., 1997a). Conversely, however, we have failed to observe any changes to this enzyme purified from isogenic prR2 mutants of $P$. gingivalis W50 in which the total extracellular Arg-specific protease levels are significantly lower than the parent strain (Aduse-Opoku et al., 1998). Hence, while the reduction in the overall proteolytic activity of the culture supernatant of W50/BE1 may have some influence on the resultant subunit organization of RI, it may not represent the only factor.

There is some evidence that the RI heterodimer may have higher virulence potential than the other isoforms. $\mathrm{HMG}$ is a more potent activator of blood coagulation through activation of factor $\mathrm{X}$ than the $50 \mathrm{kDa}$ gingipain $\mathrm{R}$ (analogous to RIA) by five- to sixfold, probably due to the adhesin domain increasing affinity to factor $\mathrm{X}$ and promoting cleavage of the substrate (Imamura et al., 1997). Activation of factor X by HMG increases in the presence of phospholipids and calcium ions, while activation by the $50 \mathrm{kDa}$ form is unaffected, perhaps due to calcium-ion-mediated binding of the adhesin domain to phospholipids. Furthermore, the $50 \mathrm{kDa}$ gingipain $\mathrm{R}$ lacks the adhesin domain and does not bind to fibronectin and other matrix proteins which coat extracellular biosurfaces in vivo. In contrast, HMG binds and degrades fibrinogen with high affinity and fibronectin and laminin with lower affinity, suggesting a role for this isoform in adhesion to host cell surfaces and interference with host clotting mechanisms (Pike et al., 1996). Low expression of $\mathrm{RI} / \mathrm{BE}$ by the mutant may consequently contribute to the avirulence of W50/BE1.

Differences were also observed between RIIA $/ B E$ and RIIA $^{\mathrm{V}} / \mathrm{BE}$ and their counterparts from the wild-type W50. N-terminal amino acid sequencing revealed that these two enzymes contained a $\sim 54 \mathrm{kDa} \alpha$-catalytic chain and $\mathrm{a} \sim 26 \mathrm{kDa}$ peptide chain derived from $p r R 2$ (Rangarajan et al., 1997b) (Fig. 3). The N-terminal amino acid sequence of the $\sim 26 \mathrm{kDa}$ peptide indicated that it was derived from the pro-region of the polyprotein. Many proteases are synthesized as inactive precursors which are dependent upon proteolytic removal of the associated pro-region for activation. These propeptides are thought to act as mediators of protein folding and intramolecular chaperones involved in stabilization and cellular localization of their associated proteases. The propeptide of cathepsin B, a cysteine protease, acts as a potent inhibitor until it is removed by autoprocessing (Fox et al., 1992). The propeptide of subtilisin $\mathrm{E}$, a serine protease, can also act as an inhibitor for its enzyme, and is essential for conversion of inactive pro-subtilisin $\mathrm{E}$ to the active form via mediation of correct folding of the subtilisin molecule (Ohta \& Inouye, 1990; Zhu et al., 1989). The propeptide of PrRII remains associated with RIIA $^{\mathrm{S}} / \mathrm{BE}$ and RIIA $\mathrm{V} / \mathrm{BE}$, even after rigorous purification, and these pure preparations are only 28 and $20 \%$ active, respectively. It is therefore possible that cleavage and dissociation of the propeptide are required for correct folding to give the mature active protease. The retention of the propeptide in these forms may reflect either modification to the processing/export of the enzyme in W50/BE1 or alteration to their extracellular processing as described above for RI/BE from this strain.

The $\alpha$-chain present in RIIA ${ }^{\mathrm{V}} / \mathrm{BE}$ did not contain large glycan modifications and this was confirmed by lack of reactivity with anti-LPS antibodies. However, RIIA ${ }^{\mathrm{V}} /$ $\mathrm{BE}$ was still associated with the membrane/vesicle fraction and required the presence of $0.05 \%$ Zwittergent to solubilize it for purification purposes. This suggests that targeting of $\mathrm{RIIA}^{\mathrm{V}} / \mathrm{BE}$ to the vesicle fraction is independent of glycan modification of the $\alpha$-catalytic chain. This is an important observation but it is not yet apparent how $\mathrm{RIIA}^{\mathrm{S}} / \mathrm{BE}$ and $\mathrm{RIIA}^{\mathrm{V}} / \mathrm{BE}$ become distributed between the soluble and membrane/vesicle fractions. Indeed, increase in soluble extracellular Argspecific protease activity at the expense of vesicleassociated activity in W50/BE1 compared to the parent strain has been previously reported (Smalley et al., 1989); the authors suggested that the enzyme from W50/BE1 may be unable to bind to or be retained on cellular and vesicular membranes. This study drew a comparison between $P$. gingivalis W50/BE1 and a 'rough' strain of Salmonella typhimurium, where extracellular accumulation of alkaline phosphatase (normally located in the periplasm) is a result of defective LPS in the outer membrane causing a change in binding affinity of the enzyme for the membrane (Lindsay et al., 1973). Recent studies on the nature of the outer membrane of $P$. gingivalis have demonstrated the loss of key antigenic determinants from the LPS of W50/BE1 compared to the parent strain (Cutler et al., 1996). It is therefore possible that membrane composition and posttranslational modification of enzyme both contribute towards the final localization of the enzymes in the parent and mutant strains.

Whilst the differences between the Arg-specific enzymes of the W50/BE1 mutant and the parent strain W50 do not significantly affect the kinetics of the enzymes measured against the small chromogenic synthetic substrate BRpNA, the structural differences may have an effect in vivo by modulating enzyme activity on physiological substrates. This is currently under further investigation. Furthermore, recent work has established a role for the Arg-specific proteases in fimbriation of the $P$. gingivalis outer membrane (Nakayama et al., 1996), and therefore disruption of these proteases may lead to disruption of fimbriae and other protease-dependent virulence determinants.

Consequently, the reduced virulence potential of W50/ BE1 may reflect an overall reduction in Arg-specific activity, altered distribution of $p r p R 1$ and $p r R 2$ products, and differently processed isoforms. The nature of the mutation(s) in W50/BE1 is currently under investigation by determination of mRNA levels and complementation studies using the parent strain $\operatorname{prp} R 1$. There may be multiple defects in gene expression at 
many loci, or alternatively a single mutation in a regulator which affects not only protease gene expression but also accessory genes involved in the processing pathway. Given the numerous phenotypic differences observed in W50/BE1 compared to the parent strain W50, and the apparent stability of the mutant, the latter hypothesis seems more likely. Therefore, further study of $P$. gingivalis W50/BE1 may provide important insights into the maturation processes of prpR1- and $p r R 2$-derived enzymes and the regulatory influences which control their expression.

\section{ACKNOWLEDGEMENTS}

This work was supported by Medical Research Council grant no. PG9318173 and by an MRC PhD studentship to L.M.C.

\section{REFERENCES}

Aduse-Opoku, J., Muir, J., Slaney, J. M., Rangarajan, M. \& Curtis, M. (1995). Characterisation, genetic analysis and expression of a protease antigen (PrpR1) of Porphyromonas gingivalis W50. Infect Immun 63, 47444754.

Aduse-Opoku, J., Rangarajan, M., Young, K. A. \& Curtis, M. A. (1998). Maturation of the arginine-specific proteases of Porphyromonas gingivalis $\mathrm{W} 50$ is dependent on a functional prR2 protease gene. Infect Immun 66, 1594-1600.

Chandad, F. \& Mouton, C. (1995). Antigenic, structural, and functional relationships between fimbriae and the hemagglutinating adhesin HA-Ag2 of Porphyromonas gingivalis. Infect Immun 63, 4755-4763.

Curtis, M. A., Aduse-Opoku, J., Slaney, J. M., Rangarajan, M., Booth, V., Cridland, J. \& Shepherd, P. (1996). Characterization of an adherence and antigenic determinant of the ArgI protease of Porphyromonas gingivalis which is present on multiple geneproducts. Infect Immun 64, 2532-2539.

Cutler, C. W., Eke, P. I., Genco, C. A., VanDyke, T. E. \& Arnold, R. R. (1996). Hemin-induced modifications of the antigenicity and hemin-binding capacity of Porphyromonas gingivalis lipopolysaccharide. Infect Immun 64, 2282-2287.

Dawson, R. M. C., Elliot, D. C., Elliot, W. H. \& Jones, K. M. (editors) (1986). Data for Biochemical Research, 3rd edn. Oxford: Clarendon Press.

Fletcher, H. M., Schenkein, H. A., Morgan, R. M., Bailey, K. A., Berry, C. R. \& Macrina, F. L. (1995). Virulence of a Porphyromonas gingivalis W83 mutant defective in the prtH gene. Infect Immun 63, 1521-1528.

Fox, T., de Miguel, E., Mort, J. S. \& Storer, A. C. (1992). Potent slow-binding inhibition of cathepsin B by its propeptide. Biochemistry 31, 12571-12576.

Good, N. E., Winget, G. D., Winter, W., Connolly, T. N., Izawa, S. \& Singh, R. M. M. (1966). Hydrogen ion buffers for biological research. Biochemistry 5, 467-477.

Han, N., Whitlock, J. \& Progulske-Fox, A. (1996). The hemagglutinin gene $\mathrm{A}$ ( $h a \mathrm{~g} A$ ) of Porphyromonas gingivalis 381 contains four large, contiguous, direct repeats. Infect Immun 64, $4000-4007$.

Hinode, D., Masuda, K., Yoshioka, M., Watanabe, K., Umemoto, T., Grenier, D., Mayrand, D. \& Nakamura, R. (1995). Immunological characterization and localization of a Porphyromonas gingivalis BApNA-hydrolyzing protease possessing hemagglutinating activity. FEMS Microbiol Lett 131, 211-217.
Imamura, T., Potempa, J., Tanase, S. \& Travis, J. (1997). Activation of blood coagulation factor $\mathrm{X}$ by arginine-specific cysteine proteinases (gingipain-R's) from Porphyromonas gingivalis. J Biol Chem 27, 16062-16067.

Kesavalu, L., Holt, S. C. \& Ebersole, J. L. (1996). Trypsin-like protease activity of Porphyromonas gingivalis as a potential virulence factor in a murine lesion model. Microb Pathog 20, $1-10$.

Laemmli, U. K. (1970). Cleavage of structural proteins during the assembly of the head of bacteriophage T4. Nature 227, 680-685.

Lindsay, S. S., Wheeler, B., Sanderson, K. E. \& Costerson, J. W. (1973). The release of alkaline phosphatase and of lipopolysaccharide during the growth of rough and smooth strains of Salmonella typhimurium. Can J Microbiol 19, 335-343.

McKee, A. S., McDermid, A. S., Wait, R., Baskerville, A. \& Marsh, P. D. (1988). Isolation of colonial variants of Bacteroides gingivalis W50 with reduced virulence. J Med Microbiol 27, 59-64.

Nakayama, K., Kadowaki, T., Okamoto, K. \& Yamamoto, K. (1995). Construction and characterization of arginine-specific cysteine proteinase (Arg-gingipain)-deficient mutants of Porphyromonas gingivalis. J Biol Chem 270, 23619-23626.

Nakayama, K., Yoshimura, F., Kadowaki, T. \& Yamamoto, K. (1996). Involvement of arginine-specific cysteine proteinase (Arggingipain) in fimbriation of Porphyromonas gingivalis. J Bacteriol $178,2818-2824$.

Ohta, Y. \& Inouye, M. (1990). Pro-subtilisin E: purification and characterization of its autoprocessing to active subtilisin $\mathrm{E}$ in vitro. Mol Microbiol 4, 295-304.

Okamoto, K., Kadowaki, T., Nakayama, K. \& Yamamoto, K. (1996). Cloning and sequencing of the gene encoding a novel lysine-specific cysteine proteinase (Lys-gingipain) in Porphyromonas gingivalis: structural relationship with the argininespecific cysteine proteinase (Arg-gingipain). J Biochem 120, 398-406.

Pavloff, N., Potempa, J., Pike, R. N., Prochazka, V., Kiefer, M. C., Travis, J. \& Barr, P. J. (1995). Molecular cloning and structural characterization of the Arg-gingipain proteinase of Porphyromonas gingivalis. J Biol Chem 270, 1007-1010.

Pike, R., McGraw, W., Potempa, J. \& Travis, J. (1994). Lysine- and arginine-specific proteinases from Porphyromonas gingivalis. $J$ Biol Chem 269, 406-411.

Pike, R. N., Potempa, J., McGraw, W., Coetzer, T. H. T. \& Travis, J. (1996). Characterization of the binding activities of proteinaseadhesin complexes from Porphyromonas gingivalis. J Bacteriol 178, 2876-2882.

Potempa, J., Pike, R. \& Travis, J. (1997). Titration and mapping of the active site of cysteine proteinases from Porphyromonas gingivalis (gingipains) using peptidyl chloromethanes. J Biol Chem 378, 223-230.

Rangarajan, M., Smith, S. J. M., U. S. \& Curtis, M. A. (1997a). Biochemical characterization of the arginine-specific proteases of Porphyromonas gingivalis W50 suggests a common precursor. Biochem J 323, 701-709.

Rangarajan, M., Aduse-Opoku, J., Slaney, J. M., Young, K. A. \& Curtis, M. A. (1997b). The $p r p R 1$ and $p r R 2$ arginine-specific proteases of Porphyromonas gingivalis W50 produce five biochemically distinct enzymes. Mol Microbiol 23, 955-965.

Shah, H. N., Seddon, S. V. \& Gharbia, S. E. (1989). Studies on the virulence properties and metabolism of pleiotropic mutants of Porphyromonas gingivalis (Bacteroides gingivalis) W50. Oral Microbiol Immunol 4, 19-23.

Smalley, J. W. \& Birss, A. J. (1991). Extracellular vesicle-associated 
and soluble trypsin-like enzyme fractions of Porphyromonas gingivalis W50. Oral Microbiol Immunol 6, 202-208.

Smalley, J. W., Birss, A. J., Kay, H. M., McKee, A. S. \& Marsh, P. D. (1989). The distribution of trypsin-like enzyme activity in cultures of a virulent and an avirulent strain of Bacteroides gingivalis W50. Oral Microbiol Immunol 4, 178-181.

van Steenbergen, T. J. N., Kastelein, P., Touw, J. J. A. \& de Graff, J. (1982). Virulence of black-pigmented Bacteroides strains from periodontal pockets and other sites in experimentally induced skin lesions in mice. J Periodontal Res 17, 41-49.

Zhu, X., Ohta, Y., Jordan, F. \& Inouye, M. (1989). Pro-sequence of subtilisin can guide the refolding of denatured subtilisin in an intramolecular process. Nature 339, 483-484.

Received 21 January 1998; revised 5 May 1998; accepted 12 May 1998. 